\title{
Effect of Wettability on Penetration and Flotation Behavior of a Particle in Refining Process
}

\author{
Akihiro MATSUZAWA, ${ }^{* 1)}$ Katsuhiro SASAI, ${ }^{1)}$ Hiroshi HARADA ${ }^{2)}$ and Mitsuhiro NUMATA ${ }^{31}$ \\ 1) R \& D Laboratories, Nippon Steel Corporation, 12 Nakamachi, Muroran City, Hokkaido, 050-8550 Japan. \\ 2) R \& D Laboratories, Nippon Steel Corporation. Now at Materials Design Innovation Engineering, Graduate School of \\ Engineering, Nagoya University, Furo-cho, Chikusa-ku, Nagoya, 464-8603 Japan. \\ 3) Steelmaking Technology Div., Nippon Steel Corporation, 2-6-1 Marunouchi, Chiyoda-ku, Tokyo, 100-8071 Japan.
}

(Received on February 9, 2021; accepted on March 15, 2021; originally published in Tetsu-to-Hagané, Vol. 106, 2020, No. 10, pp. 697-707)

\begin{abstract}
Powder blasting is often performed in refining processes for improving their reaction efficiency. Herein, the effect of wettability on penetration and flotation behavior of a particle was examined via a water model experiment. A polypropylene particle was blasted onto the water surface with Ar gas through a single-hole nozzle, and the behavior of the particle during penetration into water to flotation on the water surface was recorded using a high-speed camera. Wettability between the particle and water was changed by applying a repellent or hydrophilic material on the particle. Based on the penetration of the particle, an air column was generated and a residual bubble remained on the particle after the air column ruptured. Repellent particles floated on the water surface in a short period of time because the maximum penetration depth was short and the diameter of the residual bubble was large. Conversely, hydrophilic particles stayed longer in water than repellent particles because the maximum penetration depth was relatively long and the residual bubble detached from the particle. The mechanism which wettability affects penetration and flotation behavior was analyzed, and it was elucidated that the controlling factor of particle behavior is the adhesion point of the air column on the particle. In the case of repellent particles, the adhesion point changes toward to penetrating direction of the particle and the force caused by the surface tension of water increases. Therefore, the maximum penetration depth decreases and the diameter of the residual bubble increases.
\end{abstract}

KEY WORDS: refining process; water model experiment; wettability of a particle; air column; residual bubble; detention time of a particle.

\section{Introduction}

Powder injection ${ }^{1-5)}$ or powder blasting ${ }^{6-8)}$ is often performed in refining processes for improving their reaction efficiency. Powder injection is the method that releases powder from a lance submerged in molten steel, and powder blasting is the method that releases powder from a lance placed above molten steel against the surface of the molten steel. They are similar as a phenomenon because particles in the powder penetrate into gas-liquid interface and float on the surface of the molten steel.

Many researches ${ }^{9-25)}$ about penetration and dispersion behaviors of a particle in the liquid have been conducted and it is known that wettability between the liquid and the particle is an important factor. For example, Narita et al. ${ }^{14)}$ and Oda et al. ${ }^{15)}$ performed experiments injecting powders of various material in a water bath and reported that the

\footnotetext{
* Corresponding author: E-mail: matsuzawa.s5r.akihiro@jp.nipponsteel.com
}

penetration length and the penetration ratio of the powder with poor wettability were lower than the powder with good wettability. Also, Ogawa et al. ${ }^{16,17)}$ performed an experiment injecting flux in the molten steel and reported that flux particles with good wettability were easily dispersed.

With regard to the penetration process of the particle in the liquid, Iguchi et al. ${ }^{18-21)}$ experimentally observed in detail the falling of a particle into the water surface. According to their researches, in the case that the particle exhibited poor wettability, an air column had generated and transformed into a residual bubble owing to a part of ruptured air column remaining on the particle. Duez et al. ${ }^{22}$ ) also performed similar experiments, and suggested a mechanism of the air column being generated at the condition that the spread velocity of the liquid film on the particle is lower than the particle velocity, and formulated the equations for the threshold particle velocity of generating the air column. Furthermore, Katoh et al. ${ }^{23}$ investigated the generating process of the residual bubble via a theoretical model and 
reported that the volume of the residual bubble increases upon increasing the contact angle between the liquid and the particle. Moreover, Nakano and Ito $^{24)}$ and Nakata and Inamuro ${ }^{25}$ conducted a three dimensional calculation with regard to the penetration behavior of the particle and reported results that suggest good wettability is suitable for penetration.

Thus, there are many previous researches pertaining to the penetration and dispersion processes of the particle in the liquid. However, there are hardly researches focused on the flotation process of the particle after penetration or contact time of the particle with the liquid. Therefore, in a previous work, ${ }^{26)}$ the authors evaluated entire behavior from penetration to flotation via a water model experiment blasting a single particle to the water surface, and reported that the residual bubble on the particle significantly affects the detention time. Herein, same experiments are performed by changing the wettability of the particle, and the effect of wettability on the penetration depth and the detention time of the particle are investigated. Then, the controlling factor of the diameter of the residual bubble that affects the detention time is discussed. Also, the mechanism wherein the penetration depth decreases at poor wettability conditions is discussed.

\section{Experimental Procedures}

Experiments herein were performed using the same method as that in a previous work. ${ }^{26)}$ A predetermined amount of Ar gas was inserted into the vessel through a single-hole nozzle (5 $\mathrm{mm}$ inner diameter), which was set at the center of the upper plate of the vacuum vessel. The nozzle had a length of 70 or $140 \mathrm{~mm}$, and the water depth in the vessel before reducing the pressure was $80 \mathrm{~mm}$.

Experimental procedures are as follows. Pressure in the vessel was reduced using a vacuum pump and maintained at $52 \mathrm{kPa}$ by the vacuum regulator. Then, a single particle (polypropylene, $910 \mathrm{~kg} / \mathrm{m}^{3}$ in density, $3.2 \mathrm{~mm}$ in diameter) was blasted onto the water surface with Ar gas. The purpose of reducing the pressure in the vacuum vessel is to increase the particle velocity by increasing the Ar gas velocity. Behavior of the particle was recorded using a high-speed camera (250 frames/s), and the change in penetration depth of the particle over time was analyzed by an equation that converts the length on the monitor of the camera to the actual length. The converting equation was obtained via preliminary experiments.
Herein, wettability of the particle was changed by spraying a commercial repellent or hydrophilic material on the particle. The water droplets on a polypropylene plate sprayed repellent or hydrophilic material are shown in Fig. 1. Though the contact angle between water and polypropylene is $95^{\circ}{ }^{27)}$ it was evaluated by these images that the contact angle was $6^{\circ}$ in case of the repellent condition and $129^{\circ}$ in case of the hydrophilic condition.

Experimental conditions are shown in Table 1. The Ar flow rate, $Q_{A r}$, was $0-25 \mathrm{NL} / \mathrm{min}$, and particle blasting was conducted three times in each condition. Furthermore, conditions in previous work $\left(\theta=95^{\circ}\right), \mathrm{A} 1, \mathrm{~B} 2, \mathrm{D} 1, \mathrm{D} 2, \mathrm{E} 1$, $\mathrm{E} 2$, are listed in Table 1 because results of these conditions were analyzed with results of repellent and hydrophilic conditions herein.

Particle velocity before penetration, $\mathrm{V}_{\mathrm{P} 0}$, was measured in a different experiment. A particle releasing from the nozzle was recorded using a high-speed camera (1 000 frames/s), and the particle velocity was calculated from transport distance between two frames $(0.001 \mathrm{~s})$ just before penetration into the water surface. The particle velocity before penetration is listed in Table 1.

Table 1. Experimental conditions.

\begin{tabular}{rcrcrrr}
\hline No. & Wettability & $\begin{array}{r}\text { Contact } \\
\text { angle, } \theta \\
\left({ }^{\circ}\right)\end{array}$ & $\begin{array}{c}\text { Ar gas } \\
\text { flow rate } \\
(\mathrm{NL} / \mathrm{min})\end{array}$ & $\begin{array}{c}\text { Nozzle } \\
\text { length } \\
(\mathrm{mm})\end{array}$ & $\begin{array}{c}\text { Nozzle } \\
\text { gap } \\
(\mathrm{mm})\end{array}$ & $\begin{array}{c}\text { VP0 } \\
(\mathrm{m} / \mathrm{s})\end{array}$ \\
\hline H1 & Hydrophilic & 6 & 5 & 140 & 56 & 3.4 \\
H2 & Hydrophilic & 6 & 15 & 140 & 56 & 6.7 \\
H3 & Hydrophilic & 6 & 25 & 140 & 56 & 10.9 \\
\hline R1 & Repellent & 129 & 0 & 70 & 126 & 1.7 \\
R2 & Repellent & 129 & 15 & 70 & 126 & 5.9 \\
R3 & Repellent & 129 & 25 & 70 & 126 & 7.2 \\
R4 & Repellent & 129 & 25 & 140 & 56 & 10.9 \\
\hline *A1 & Normal & 95 & 0 & 70 & 126 & 1.7 \\
*B2 & Normal & 95 & 5 & 140 & 56 & 3.4 \\
*D1 & Normal & 95 & 15 & 70 & 126 & 5.9 \\
*D2 & Normal & 95 & 15 & 140 & 56 & 6.7 \\
*E1 & Normal & 95 & 25 & 70 & 126 & 7.2 \\
*E2 & Normal & 95 & 25 & 140 & 56 & 10.9 \\
\hline
\end{tabular}

* Conditions in previous work. ${ }^{26)}$

$\mathrm{V}_{\mathrm{P} 0}$ : Particle velocity before penetration

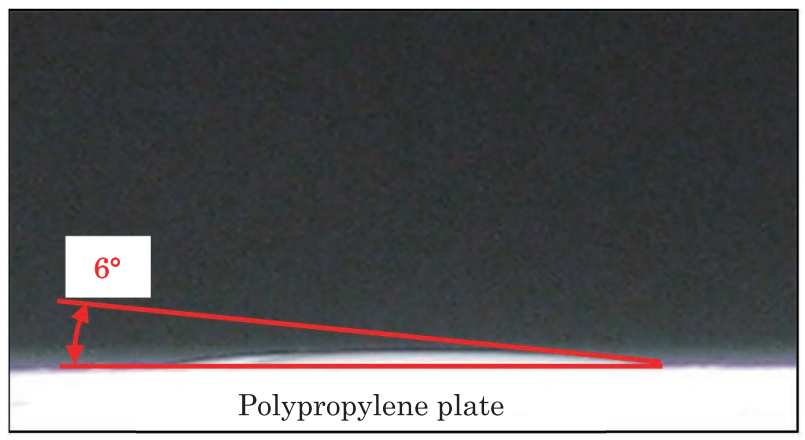

(a) Polypropylene plate with hydrophilic material.

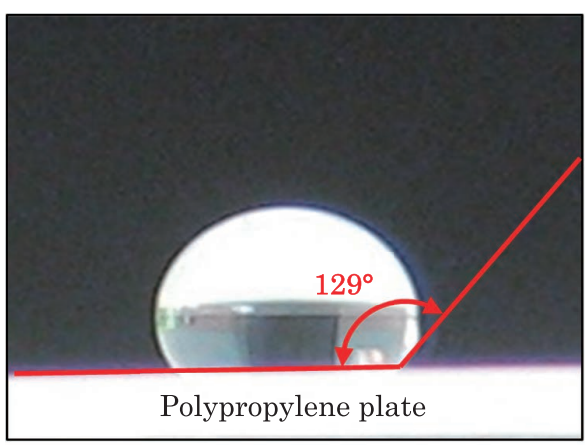

(b) Polypropylene plate with repellent material.

Fig. 1. Contact angle between water droplet and polypropylene plate with hydrophilic or repellent material. 


\section{Experimental Results}

\subsection{Changes of Penetration Depth over Time of a Particle}

Recorded images in case R3 $\left(\theta=129^{\circ}\right)$ are shown in Fig. 2 as an example of penetration and flotation behaviors. The water surface was deformed by particle penetration and an air column was generated. When the air column was ruptured, a part of the air column remained on the particle and transformed into a residual bubble (the diameter was $4.3 \mathrm{~mm}$ in Fig. 2). After the rupture of the air column, the particle penetrated until it reached the maximum depth and floated on the water surface.

Recorded images in the case H2 $\left(\theta=6^{\circ}\right)$ is shown in Fig. 3. Particle behavior until the rupture of the column was similar as that shown in Fig. 2, and a bubble (the diameter was $3.0 \mathrm{~mm}$ in Fig. 3) remained on the particle. However, the residual bubble detached and the particle floated on the water surface without the residual bubble.

Changes in the penetration depth over time are shown in Fig. 4. Effect of the wettability was unclear at lower $\mathrm{V}_{\mathrm{P} 0}$, in the case (a) and (b); however, the penetration depth decreased with increasing $\theta$ and floated for a short period of time in the case (c)-(f) wherein $\mathrm{V}_{\mathrm{P} 0}$ was higher than 5 $\mathrm{m} / \mathrm{s}$. Conversely, the flotation time was long in the case of
$\mathrm{H} 2$ and $\mathrm{H} 3\left(\theta=6^{\circ}\right)$. It is because a residual bubble is not generated or it detached from the particle.

Analyzed factors from images captures using the highspeed camera are shown in Fig. 5. ${ }^{26}$ (a) Particle velocity after penetration, $\mathrm{V}_{\mathrm{P} 1}$, was calculated using the transfer distance between two frames $(0.004 \mathrm{~s})$ just after penetration into the water surface. (b) Maximum air column length, $\mathrm{H}_{\max }$, was defined as the distance from the base point to upper side of the particle just before rupture of the air column, and (c) maximum penetration depth, $\mathrm{L}_{\max }$, was defined as the distance from the base point to center of the particle at maximum depth. The base point indicates the cavity depth of the water surface before penetration. (d) Diameter of a residual bubble, $\mathrm{d}_{\mathrm{B}}$, was measured at the moment when the shape of the bubble became nearly spherical. (e) Average flotation velocity was obtained via the liner regression calculation of the change of penetration depth over time during the period that particle flotation velocity became almost constant. (f) Detention time of the particle was defined as the period from the rupture of the air column to flotation toward the water surface. In some conditions, the particle hid behind a cavity of the water surface before reaching the surface. Therefore, the detention time was calculated by extrapolating the liner regression equation calculating average flotation velocity to the water surface.

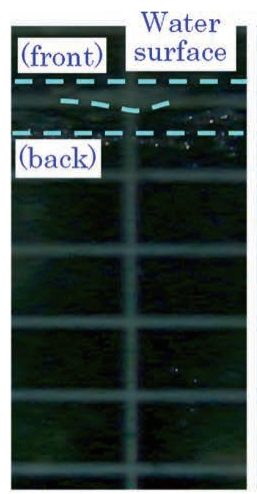

Os

Just before penetration

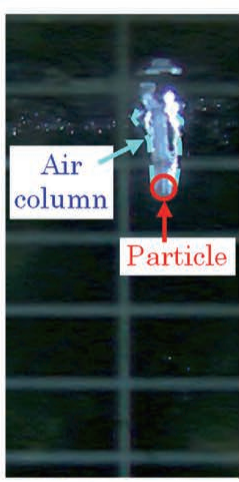

$0.004 \mathrm{~s}$ Just after penetration

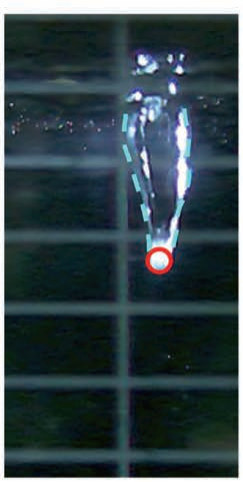

$0.012 \mathrm{~s}$ Extension of an air column

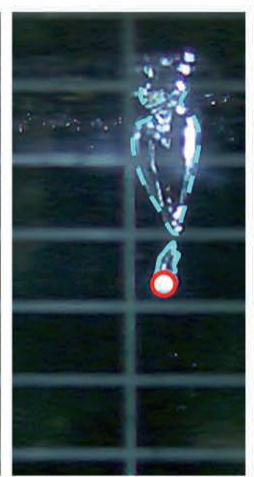

$0.020 \mathrm{~s}$

Rupture of an air column

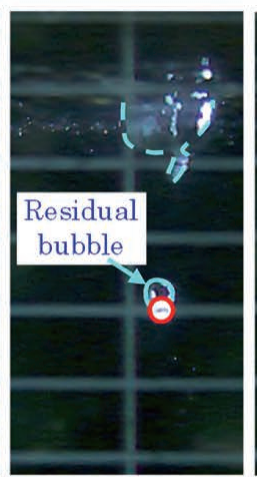

$0.044 \mathrm{~s}$ Maximum depth

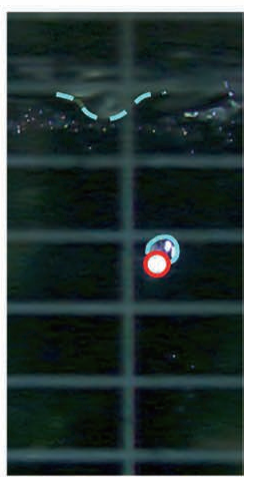

$0.084 \mathrm{~s}$ Flotation

Fig. 2. Penetration and flotation behavior of a particle (Condition R3, $\theta=129^{\circ}$ ).

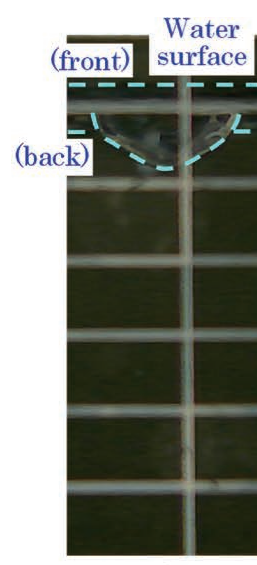

$0 \mathrm{~s}$

Just before penetration

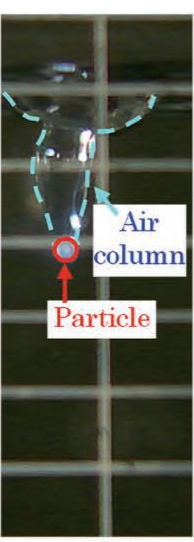

$0.004 \mathrm{~s}$ Just after penetration

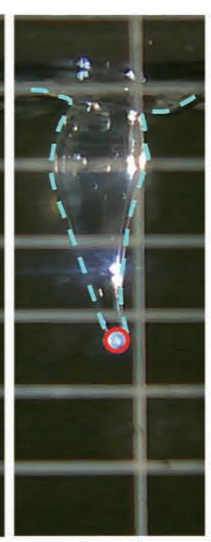

$0.012 \mathrm{~s}$

Extension of an air column

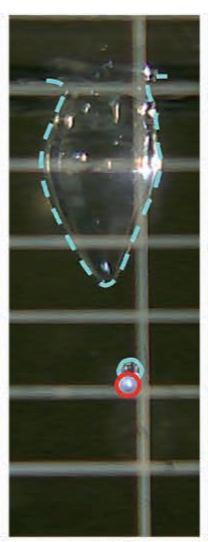

$0.020 \mathrm{~s}$

Rupture of

Bubble detachment Maximum
from the particle depth
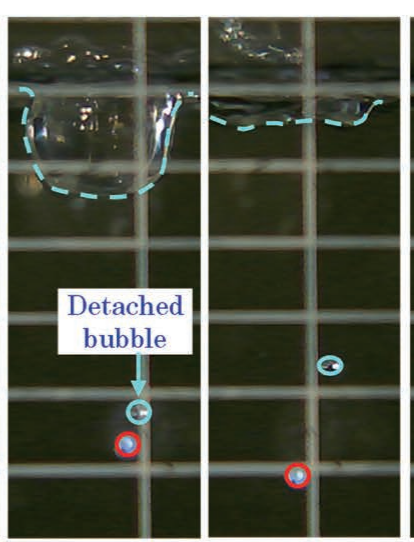

$0.104 \mathrm{~s}$

Fig. 3. Penetration and flotation behavior of a particle (Condition $\mathrm{H} 2, \theta=6^{\circ}$ ).

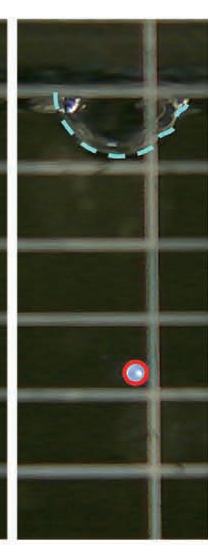

$0.460 \mathrm{~s}$

Flotation 
ISIJ International, Vol. 61 (2021), No. 7

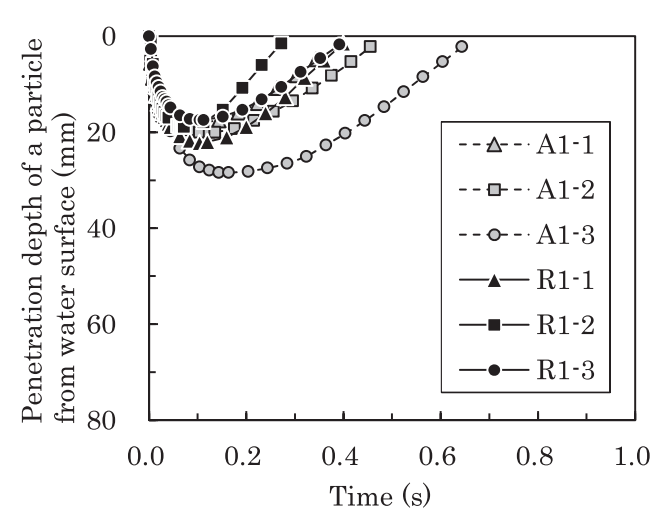

(a) $\mathrm{v}_{\mathrm{P} 0}=1.7 \mathrm{~m} / \mathrm{s}$

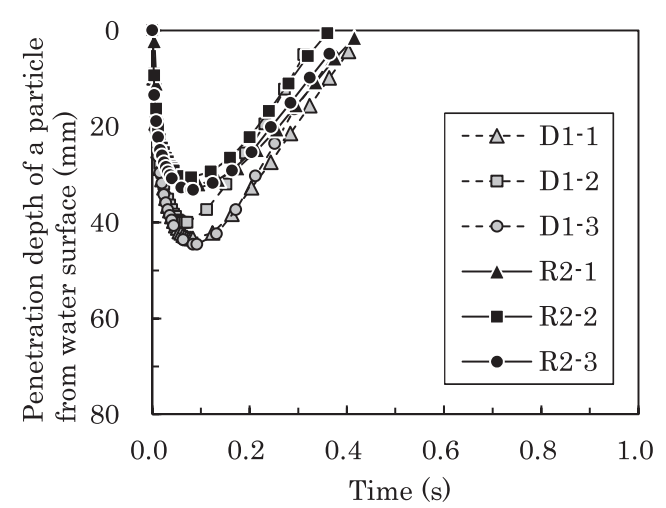

(c) $\mathrm{v}_{\mathrm{P} 0}=5.9 \mathrm{~m} / \mathrm{s}$

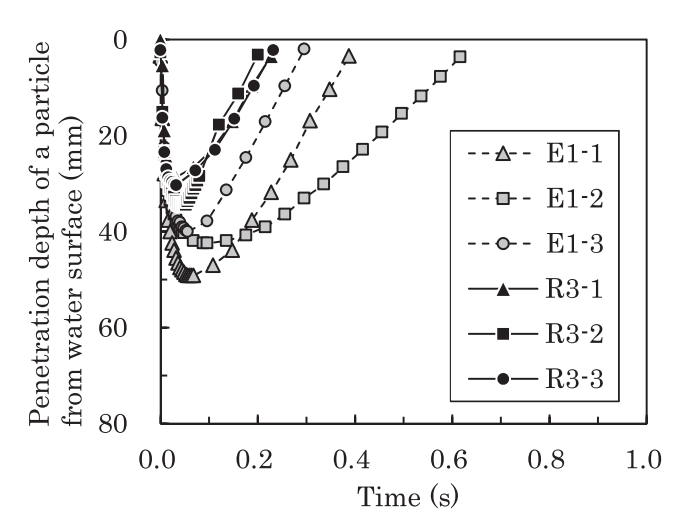

(e) $\mathrm{v}_{\mathrm{PO}}=7.2 \mathrm{~m} / \mathrm{s}$

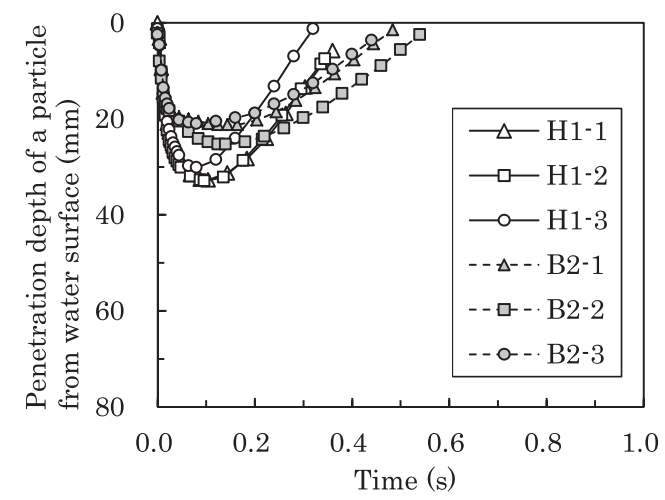

(b) $\mathrm{v}_{\mathrm{P} 0}=3.4 \mathrm{~m} / \mathrm{s}$

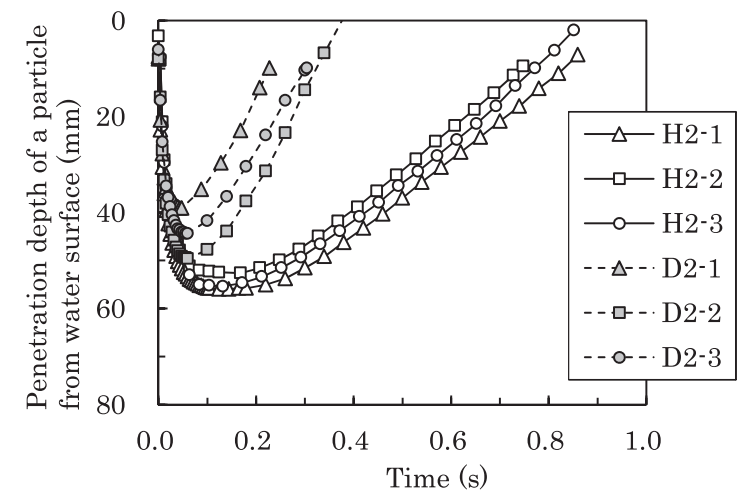

(d) $\mathrm{v}_{\mathrm{P} 0}=6.7 \mathrm{~m} / \mathrm{s}$

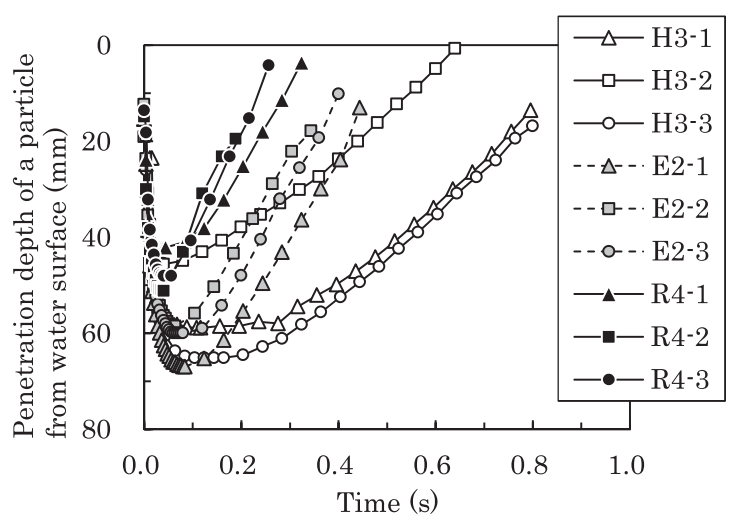

(f) $\mathrm{v}_{\mathrm{P} 0}=10.9 \mathrm{~m} / \mathrm{s}$

*A1, B2, D1, D2, E1, E2: Previous work ${ }^{26)}\left(\theta=95^{\circ}\right)$

$\mathrm{H} 1, \mathrm{H} 2, \mathrm{H} 3 \quad$ : Present work $\left(\theta=6^{\circ}\right)$

R1, R2, R3, R4 : Present work $\left(\theta=129^{\circ}\right)$

Fig. 4. Change of penetration depths of a particle from water surface with time.

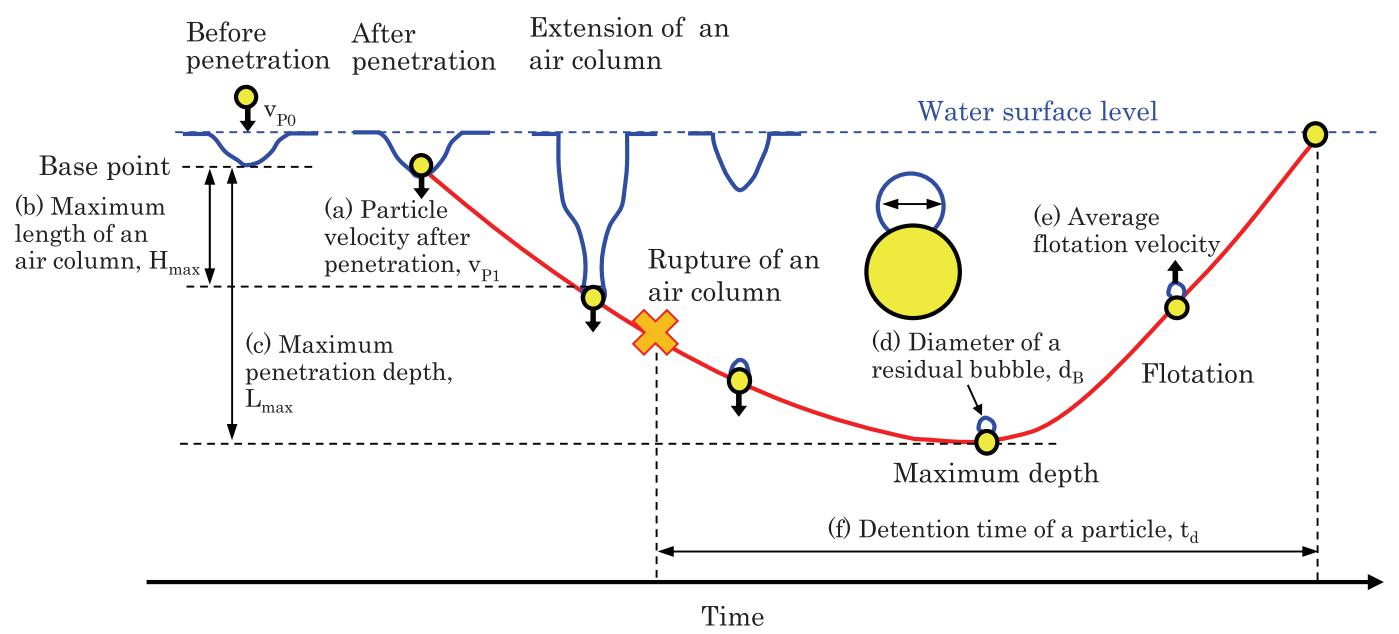

Fig. 5. Schematic diagram of a particle behavior and analyzed factors in present work. ${ }^{26)}$ (Online version in color.) 
Experimental data obtained herein are shown in Table 2. Although an air column was generated in all cases, a residual bubble was not shown in the case H3-1 and R1-3. In addition, a residual bubble detached from the particle in $0.020-0.076$ $\mathrm{s}$ after the rupture of an air column in the three cases of $\mathrm{H} 2$, H3-2, and H3-3. The cases H3-2, R3-1, R3-3, and R4-1 in Table 2 were eliminated from analysis because the point of maximum depth shifted toward the horizontal direction more than $20^{\circ}$ from penetrating point at the water surface.

\subsection{Particle Velocity after Penetration}

Comparison of the particle velocity after penetration, $\mathrm{v}_{\mathrm{P} 1}$, with the particle velocity before penetration, $\mathrm{v}_{\mathrm{P} 0}$, is shown in Fig. 6. The particle velocity significantly decreased from $1.7-10.9 \mathrm{~m} / \mathrm{s}$ to $0.9-3.8 \mathrm{~m} / \mathrm{s}$ by penetration; however, the effect of wettability was not considered. Thus, it is supposed that the effect of wettability upon consuming the kinetic energy of the particle is minor at the penetration to the water surface.

\subsection{Maximum Length of an Air Column and Maxi- mum Penetration Depth}

Effect of $\mathrm{v}_{\mathrm{P} 0}$ on $\mathrm{H}_{\max }$ is shown in Fig. 7. $\mathrm{H}_{\max }=0 \mathrm{~mm}$ implies that an air column was not generated. In the case of $\theta=95^{\circ}$, the air column was not generated when VP0 was lower than $3.4 \mathrm{~m} / \mathrm{s}$. Conversely, in the case of $\theta=129^{\circ}$, the air column was generated although $\mathrm{V}_{\mathrm{P} 0}$ was $1.7 \mathrm{~m} / \mathrm{s}$. It was reported that the threshold velocity of the generated column decreased with an increasing $\theta$ when $\theta$ was larger than $90^{\circ},{ }^{22)}$ and same result was obtained herein. In Fig. 7 , the tendency that $\mathrm{H}_{\max }$ increases with an increasing $\mathrm{V}_{\mathrm{P} 0}$ at each contact angle was considered; however, $\mathrm{H}_{\max }$ at $\theta=$ $129^{\circ}$ was slightly shorter than $\mathrm{H}_{\max }$ at $\theta=6^{\circ}$ or $95^{\circ}$.

Effect of $\mathrm{v}_{\mathrm{P} 0}$ on $\mathrm{L}_{\max }$ is shown in Fig. 8. The tendency

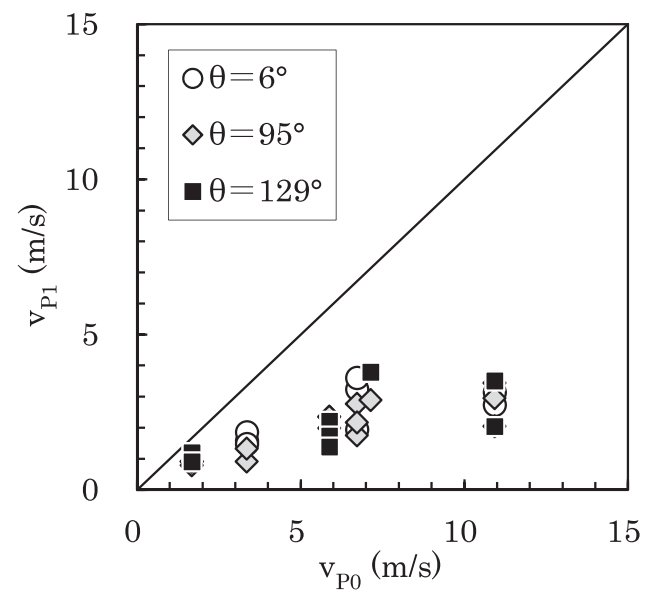

Fig. 6. Comparison of particle velocity before penetration and after penetration.

Table 2. Experimental results

\begin{tabular}{|c|c|c|c|c|c|c|c|c|}
\hline \multicolumn{2}{|c|}{ No. } & $\begin{array}{l}\text { Particle velocity } \\
\text { after penetration, } \\
\qquad V_{P 1}(\mathrm{~m} / \mathrm{s})\end{array}$ & $\begin{array}{c}\text { Maximum length } \\
\text { of an air column, } \\
\mathrm{H}_{\max }(\mathrm{mm})\end{array}$ & $\begin{array}{c}\text { Maximum } \\
\text { penetration depth, } \\
\mathrm{L}_{\max }(\mathrm{mm})\end{array}$ & $\begin{array}{l}\text { Diameter of a } \\
\text { residual bubble, } \\
\mathrm{d}_{\mathrm{B}}(\mathrm{mm})\end{array}$ & $\begin{array}{c}\text { Average } \\
\text { penetration } \\
\text { angle }\left(^{\circ}\right)\end{array}$ & $\begin{array}{c}\text { Average } \\
\text { flotation } \\
\text { velocity }(\mathrm{m} / \mathrm{s})\end{array}$ & $\begin{array}{c}\text { Detention } \\
\text { time of } \mathrm{a} \\
\text { particle, } \mathrm{t}_{\mathrm{d}}(\mathrm{s})\end{array}$ \\
\hline \multirow{3}{*}{ H1 } & 1 & 1.6 & 21.2 & 32.7 & 2.0 & 4.5 & 0.130 & 0.378 \\
\hline & 2 & 1.8 & 21.6 & 31.7 & 2.1 & 5.3 & 0.128 & 0.376 \\
\hline & 3 & 1.5 & 17.7 & 28.9 & 2.0 & 19.0 & 0.136 & 0.310 \\
\hline \multirow{3}{*}{$\mathrm{H} 2$} & 1 & 1.9 & 30.5 & 48.3 & $3.0(0) *$ & 3.5 & 0.080 & 0.938 \\
\hline & 2 & 3.2 & 32.7 & 49.4 & $2.4(0) *$ & 4.5 & 0.084 & 0.842 \\
\hline & 3 & 3.6 & 29.3 & 48.1 & $2.4(0) *$ & 1.3 & 0.087 & 0.863 \\
\hline \multirow{3}{*}{$\mathrm{H} 3$} & 1 & 3.1 & 34.1 & 43.5 & 0.0 & 5.1 & 0.091 & 0.933 \\
\hline & 2 & 2.9 & 22.5 & 26.5 & $3.2(0) *$ & 26.6 & 0.089 & $0.633^{* *}$ \\
\hline & 3 & 2.7 & 36.1 & 51.7 & $2.7(0) *$ & 1.0 & 0.091 & 0.963 \\
\hline \multirow{3}{*}{ R1 } & 1 & 1.2 & 12.3 & 22.0 & 0.9 & 5.0 & 0.089 & 0.394 \\
\hline & 2 & 1.2 & 9.2 & 18.9 & 1.8 & 17.5 & 0.112 & 0.268 \\
\hline & 3 & 0.9 & 8.0 & 17.5 & 0.0 & 5.5 & 0.070 & 0.394 \\
\hline \multirow{3}{*}{$\mathrm{R} 2$} & 1 & 2.2 & 21.4 & 32.0 & 1.5 & 10.1 & 0.116 & 0.405 \\
\hline & 2 & 1.7 & 22.8 & 30.6 & 1.7 & 9.7 & 0.132 & 0.341 \\
\hline & 3 & 1.4 & 23.3 & 33.2 & 1.7 & 7.0 & 0.117 & 0.390 \\
\hline \multirow{3}{*}{ R3 } & 1 & 3.4 & 27.3 & 28.9 & 2.0 & 30.0 & 0.165 & $0.220 * *$ \\
\hline & 2 & 3.8 & 25.1 & 31.9 & 4.1 & 1.7 & 0.211 & 0.198 \\
\hline & 3 & 1.8 & 25.6 & 28.1 & 2.3 & 28.1 & 0.163 & $0.228^{* *}$ \\
\hline \multirow{3}{*}{$\mathrm{R} 4$} & 1 & 2.0 & 24.6 & 27.8 & 3.2 & 23.3 & 0.173 & $0.324 * *$ \\
\hline & 2 & 2.0 & 29.2 & 36.3 & 4.3 & 5.5 & 0.170 & 0.280 \\
\hline & 3 & 3.5 & 26.4 & 34.4 & 4.0 & 16.1 & 0.225 & 0.259 \\
\hline
\end{tabular}

* Detaching the residual bubble from the particle after rupture of the air column.

** Unavailable result for analysis because average penetration angle is larger than $20^{\circ}$. 


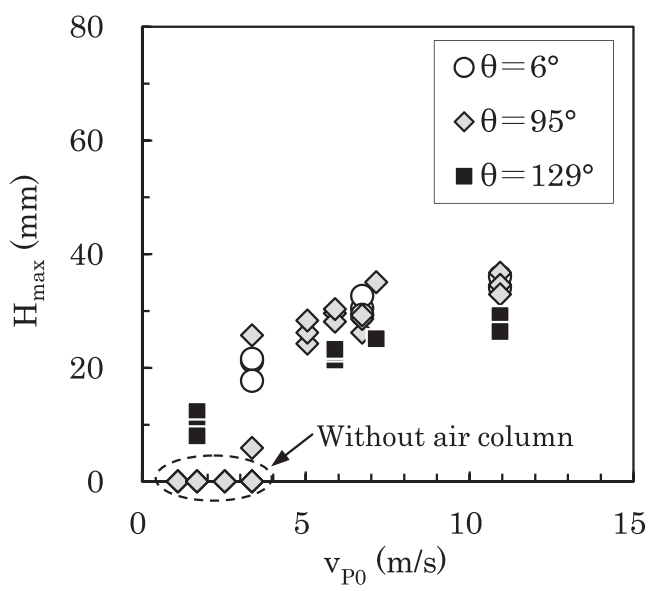

Fig. 7. Effect of particle velocity before penetration on maximum length of an air column.

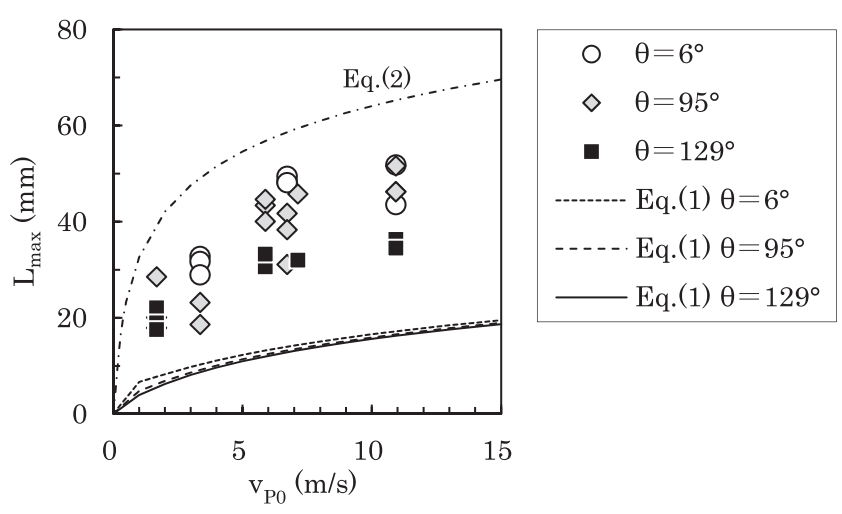

Fig. 8. Effect of particle velocity before penetration on maximum penetration depth.

that $\mathrm{L}_{\max }$ increases with an increasing $\mathrm{V}_{\mathrm{P} 0}$ at $\theta=6^{\circ}$ or $129^{\circ}$ as well as at $\theta=95^{\circ}$ is considered. However, $\mathrm{L}_{\max }$ at $\theta=$ $129^{\circ}$ is shorter than $\mathrm{L}_{\max }$ at $\theta=6^{\circ}$ or $95^{\circ}$ when $\mathrm{V}_{\mathrm{P} 0}$ is larger than $5.9 \mathrm{~m} / \mathrm{s}$. This cause behind the same will be discussed in section 4.3 .

According to the kinetic equation of a particle by Ozawa et al., $\left.{ }^{6}\right)$ Eq. (1) was established considering effect of the surface tension of liquid.

$$
\begin{aligned}
& v_{P 0}{ }^{2} \cdot \exp \left\{-\frac{3 C_{D} \varphi_{1}}{4\left(\rho_{P} / \rho_{L}+\alpha\right)} \cdot \frac{L_{\max }}{r_{P}}\right\}-\frac{4 A \sigma_{G L}}{r_{P} \rho_{L} C_{D} \varphi_{1}} \cdot \frac{L_{\max }}{r_{P}}+ \\
& {\left[\frac{4 A \sigma_{G L}}{r_{P} \rho_{L} C_{D} \varphi_{1}}\left\{\frac{4\left(\rho_{P} / \rho_{L}+\alpha\right)}{3 C_{D} \varphi_{1}}+1+\cos \theta\right\}+\frac{8 r_{P} g\left(\rho_{P} / \rho_{L}-\varphi_{2}\right)}{3 C_{D} \varphi_{1}}\right]} \\
& \cdot\left[1-\exp \left\{-\frac{3 C_{D} \varphi_{1}}{4\left(\rho_{P} / \rho_{L}+\alpha\right)} \cdot \frac{L_{\max }}{r_{P}}\right\}\right]=0
\end{aligned}
$$

Where, the drag coefficient, $C_{D}$, is 0.44 , the radius of the particle, $r_{\mathrm{P}}$, is $0.016 \mathrm{~m}$, the particle density, $\rho_{\mathrm{P}}$, is $910 \mathrm{~kg} / \mathrm{m}^{3}$, the liquid density, $\rho_{\mathrm{L}}$, is $1000 \mathrm{~kg} / \mathrm{m}^{3}$, the surface tension of liquid, $\sigma_{\mathrm{GL}}$, is $0.073 \mathrm{~N} / \mathrm{m},{ }^{28)}$ and the gravitational acceleration, $g$, is $9.8 \mathrm{~m} / \mathrm{s}^{2}$. Furthermore, $\mathrm{A}$ is the proportional coefficient of the interfacial tension for generating a cavity on the liquid surface, $\alpha$ is the coefficient related to imaginary mass (-), $\varphi_{1}$ and $\varphi_{2}$ are the coefficient related to the drag coefficient and the buoyancy force, respectively. Calculated values of $\mathrm{L}_{\max }\left(\mathrm{A}=2.5, \alpha=0.25, \varphi_{1}=1\right.$, and $\left.\varphi_{1}=0.5\right)$ are shown in Fig. 8. They were significantly smaller than the observed values herein, and the difference of $\mathrm{L}_{\max }$ by wettability was hardly shown.

If ignoring the effect of the surface tension $(\mathrm{A}=0), \mathrm{L}_{\max }$ is expressed using Eq. (2).

$$
L_{\max }=\frac{4 r_{P}\left(\rho_{P} / \rho_{L}+\alpha\right)}{3 C_{D} \varphi_{1}} \ln \left\{1-\frac{3 C_{D} \varphi_{1} v_{P 0}^{2}}{8 r_{P} g\left(\rho_{P} / \rho_{L}-\varphi_{2}\right)}\right\} \ldots
$$

The value calculated ( $\alpha=0.5, \varphi_{1}=1$, and $\varphi_{2}=1$ ) using Eq. (2) is also shown in Fig. 8; it was larger than the observed values. Although the particle consumes the kinetic energy by the surface tension, it is supposed that the effect of the surface tension herein is minor than that observed in mercury model experiment by Ozawa et al. ${ }^{11)}$

\subsection{Diameter of a Residual Bubble and Average Flota- tion Velocity of a Particle}

Effect of $\mathrm{V}_{\mathrm{P} 0}$ on $\mathrm{d}_{\mathrm{B}}$ is shown in Fig. 9. Arrows in the figure imply $d_{B}$ is the value before detachment from the particle. Although $\mathrm{d}_{\mathrm{B}}$ have scatter, they increased with an increasing $\mathrm{V}_{\mathrm{P} 0}$ in the case $\theta=95^{\circ}$ and $129^{\circ}$. Conversely, the residual bubble detached from the particle in the case of $\theta=6^{\circ}$ when $\mathrm{V}_{\mathrm{P} 0}$ is higher than $6.7 \mathrm{~m} / \mathrm{s}$. The supposed causes reported are that wetting process on the particle proceeds easily until flotation on the water surface as the penetration depth increases with an increasing $\mathrm{V}_{\mathrm{P} 0}$, or that fluid of the water accompanying movement of the particle may be strengthened with an increasing $\mathrm{V}_{\mathrm{P} 0}$.

Relation between $H_{\max }$ and $d_{B}$ is shown in Fig. 10. The tendency that $d_{B}$ increases with an increasing $\mathrm{H}_{\max }$ is considered. The effect of $\theta$ on generating an air column will be discussed in section 4.1 , and the effect of $\theta$ on $d_{B}$ will be discussed in section 4.2.

The effect of $d_{B}$ on the average flotation velocity of a particle is shown in Fig. 11. $\theta$ did not influence the average flotation velocity. Compared with the calculated values of the terminal velocity considering the apparent density of the particle as the previous work, ${ }^{26)}$ the observed values were a slightly lower than the calculated values in the case wherein $\mathrm{d}_{\mathrm{B}}$ was larger than $2 \mathrm{~mm}$. The supposed cause behind the same is that an increasing $d_{B}$ leads to an increase in the projection cross-section area of the particle, including the bubble and the friction force between the water and the particle being increased.

\subsection{Detention Time of a Particle}

Relation between $\mathrm{L}_{\max }$ and $t_{d}$ is shown in Fig. 12. The left side of the figure, i.e., (a), was classified by $\theta$. In the case of $\theta=129^{\circ}, \mathrm{t}_{\mathrm{d}}$ did not increase although $\mathrm{L}_{\max }$ increased. Conversely, $t_{d}$ increased with an increasing $L_{\max }$ in the case of $\theta=6^{\circ}$. Next, the right side of the figure, i.e., (b), was classified by $\mathrm{d}_{\mathrm{B}}$. Experimental data were separated into two groups corresponding to $d_{B}$. The same result as that of the previous work ${ }^{26}$ was obtained although the contact angle was changed. Therefore, effect of $d_{B}$ on $t_{d}$ did not depend on the wettability of the particle. Moreover, four plots (in the dashed circle at the figure) above the group that $d_{B}$ is larger than $2 \mathrm{~mm}$ comprise particle that are detached by the residual bubble, and any their contact angle is $6^{\circ}$. Thus, 


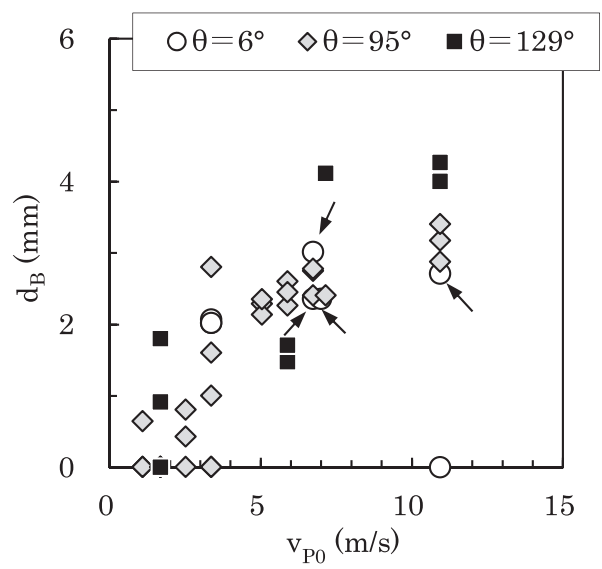

Fig. 9. Effect of particle velocity before penetration on diameter of a residual bubble (Arrow means that the bubble was detached from the particle in water.).

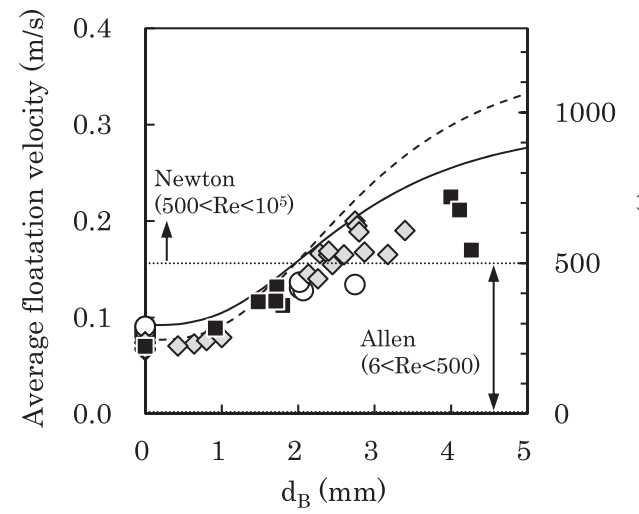

Fig. 11. Effect of diameter of a residual bubble on average floatation velocity of a particle.
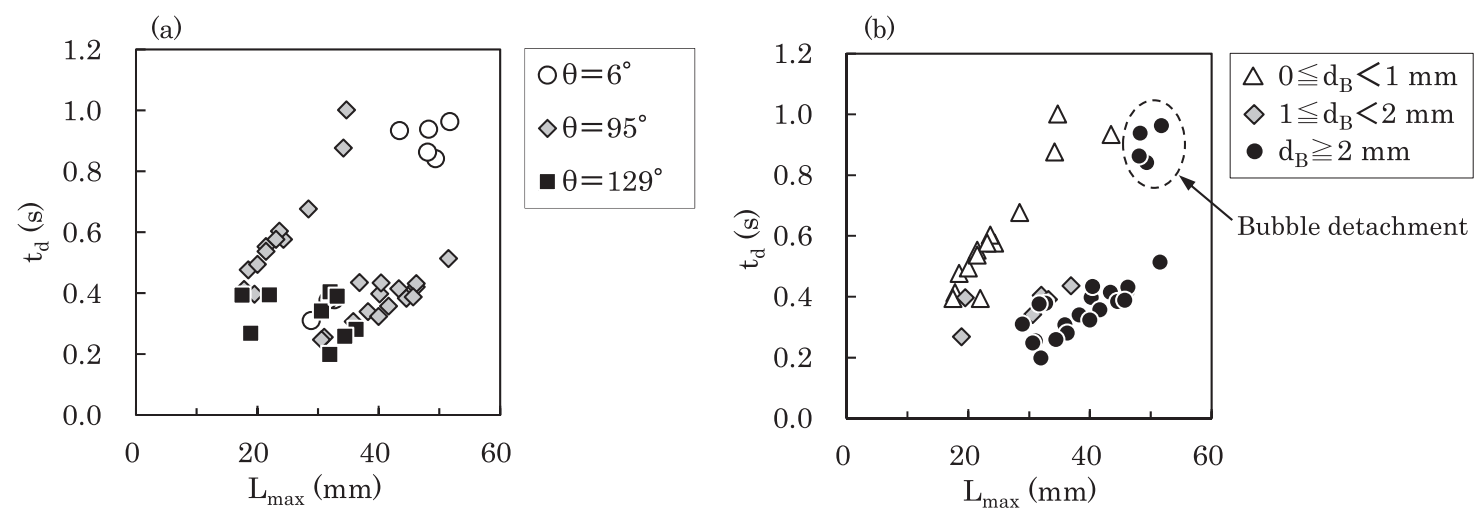

Fig. 12. Relation between maximum penetration depth and detention time of a particle.

it is supposed that the detention time of the particle may increase by penetrating the particle with good wettability at high velocity because it penetrates deeply and floats slowly owing to detaching the residual bubble readily.

\section{Discussions}

An air column generated via particle penetration creates a residual bubble and decreases the detention time of the particle. Therefore, the relation between the threshold particle velocity of generating an air column and the contact angle was analyzed in section 4.1. Then, the mechanism wherein the diameter of the residual bubble was changed

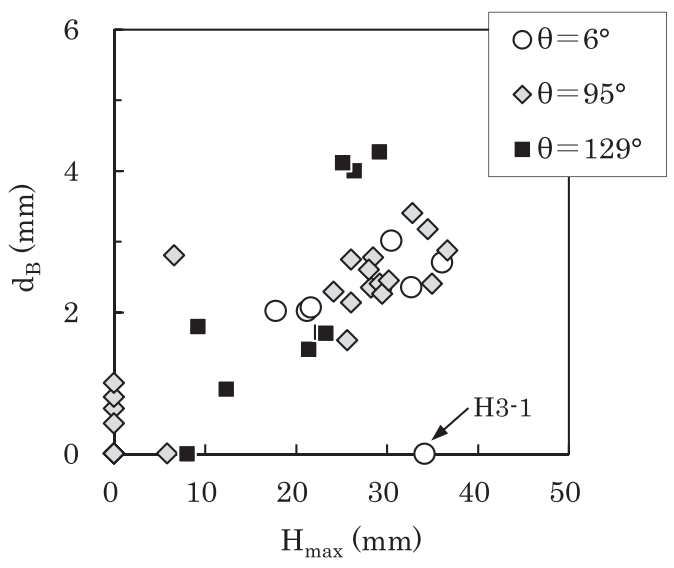

Fig. 10. Relation between maximum length of an air column and diameter of a residual bubble.

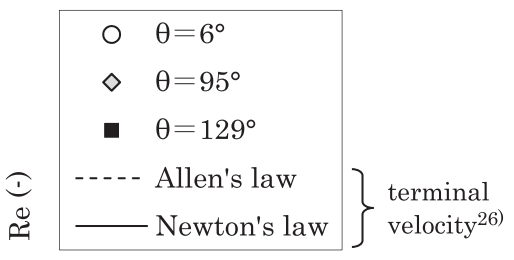


lated value from the empirical equation of $\mathrm{v}_{\mathrm{P}}{ }^{*}$ reported by Duez et $a l .{ }^{22)}$ Herein, the air column was generated in the region wherein $\mathrm{V}_{\mathrm{P} 0}$ was lower than the solid line. The dashed line in Fig. 13 indicates the estimated value of $\mathrm{v}_{\mathrm{P}}{ }^{*}$ herein, and it is supposed that $\mathrm{V}_{\mathrm{P}}{ }^{*}$ is approximately $3.0 \mathrm{~m} / \mathrm{s}$ at $\theta \leqq$ $90^{\circ}$ although $\mathrm{v}_{\mathrm{P}}{ }^{*}$ is $7.3 \mathrm{~m} / \mathrm{s}$ from the empirical equation.

Experimental conditions in Duez's research and present work are shown in Table 3. Difference between this work against Duez's research are as follows: (a) the diameter of the particle is small, (b) the density ratio of the particle and the liquid is small, (c) the particle is blasted by career gas, and (d) the pressure above the water surface is reduced. At first, in Duez's experiment, $\mathrm{v}_{\mathrm{P}}{ }^{*}$ at $\theta \leqq 90^{\circ}$ was almost same although the diameter of a particle was varied from 7.0 to $25.4 \mathrm{~mm}$. Thus, it is supposed that the effect of the diameter of a particle on $\mathrm{V}_{\mathrm{P}}{ }^{*}$ is minor. Next, lowering the particle density than the liquid density increases the buoyancy force and it proceeds to spread the liquid film on the particle. Thus, it is supposed that $\mathrm{v}_{\mathrm{P}}{ }^{*}$ increases by decreasing the density ratio of the particle and the liquid. Conversely, it is supposed that blasting a particle by career gas can decrease $\mathrm{v}_{\mathrm{P}}{ }^{*}$ because the water surface is deformed by the gas and an air column is generated easier than free fall (without career gas) condition. Then, at the free fall condition, it is estimated that the pressure above the water surface hardly affects $v_{P}{ }^{*}$. However, at the particle blasting condition, $\mathrm{v}_{\mathrm{P}}{ }^{*}$ can be possibly lowered by reducing the pressure owing to an increase in the gas velocity although the gas flow rate is constant, and deformation of the water surface increases. Therefore, it is supposed that (c) and (d) lead to lower $\mathrm{v}_{\mathrm{P}}{ }^{*}$ herein; however, more investigation pertaining to the effect of the pressure on $\mathrm{v}_{\mathrm{P}}{ }^{*}$ is necessary.

\subsection{Effect of Adhesion Point of Air Column on Diame- ter of Residual Bubble}

Sakai and Iguchi $^{21)}$ evaluated the adhesion point of an air column on a particle using the index, separation angle of an air column. Thus, the separation angle of an air column was also evaluated herein. Then, the effect of the contact angle on the separation angle and relation between the separation angel and the diameter of the residual bubble were analyzed.

Schematic diagram of an air column on a particle is shown in Fig. 14(a). The separation angle was defined as

Table 3. Comparison of experimental conditions between the previous work and present work.

\begin{tabular}{|c|c|c|c|c|}
\hline Author & Particle & Liquid & $\begin{array}{l}\text { Blasting } \\
\text { method }\end{array}$ & $\begin{array}{c}\text { Pressure } \\
\text { above liquid } \\
\text { surface }\end{array}$ \\
\hline Duez $^{22)}$ & $\begin{array}{c}\text { Diameter: } \\
\text { 7.0-25.4 mm } \\
\text { Material: } \\
\text { Glass/Al/Steel }\end{array}$ & $\begin{array}{c}\text { Water } \\
\text { Isopropanol } \\
\text { Ehtanol } \\
\text { Water-glycerol }\end{array}$ & Free fall & Atmospheric \\
\hline $\begin{array}{c}\text { Present } \\
\text { work }\end{array}$ & $\begin{array}{c}\text { Diameter: } \\
3.2 \mathrm{~mm} \\
\text { Material: } \\
\text { Polypropylene }\end{array}$ & Water & Ar gas & $\begin{array}{l}\text { Reduced } \\
(52 \mathrm{kPa})\end{array}$ \\
\hline
\end{tabular}

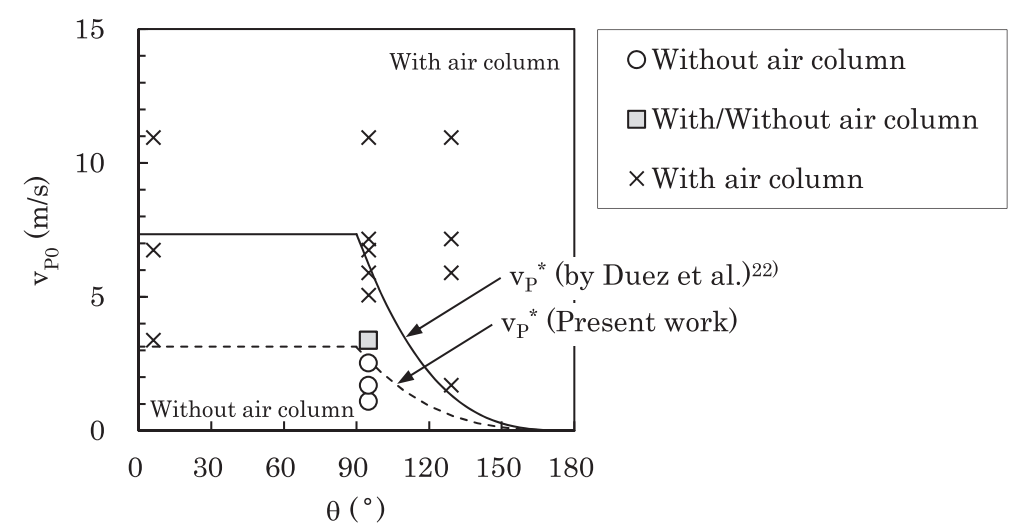

Fig. 13. Comparison of experimental results in present work and threshold particle velocity of generating an air column, $\mathrm{v}_{\mathrm{P}}{ }^{*}$.

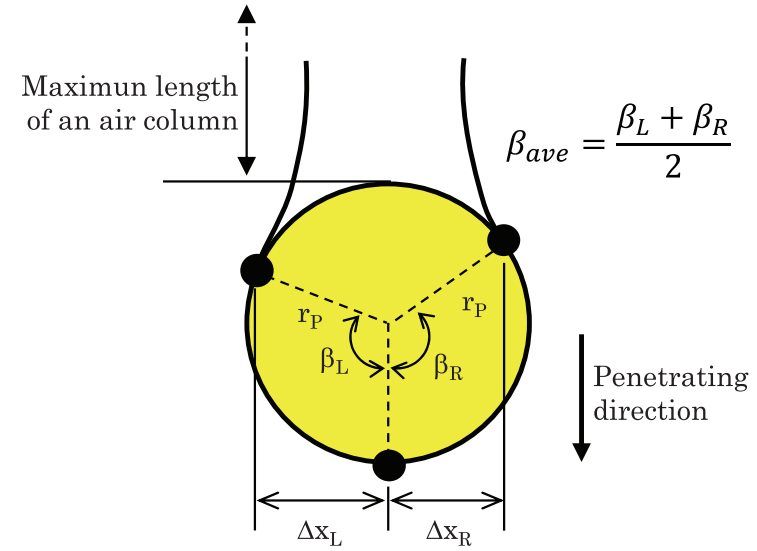

(a) Before rupture of the air column

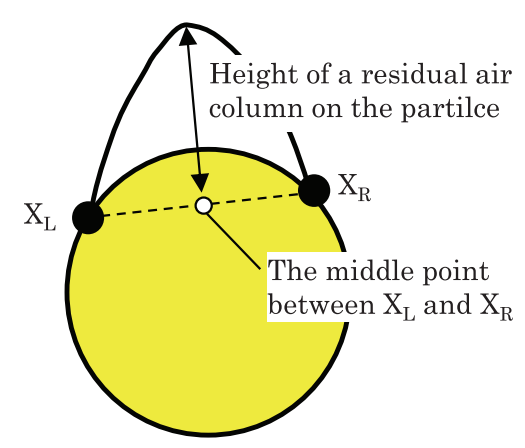

(b) After rupture of the air column

Fig. 14. Schematic diagram of the air column on the particle. (Online version in color.) 
the angle between the adhesion point of the air column on the particle (three-phase boundary of the particle, the liquid and the air column) and tip of the particle to the penetrating direction against the weight center of the particle just before rupture of the air column. A lower separation angle implies that the adhesion point of the air column is located on the front side of the particle against the center of the particle. With regard to the separation angle at left side of the particle, $\beta_{\mathrm{L}}\left(^{\circ}\right), \sin \left(180^{\circ}-\beta_{L}\right)=\Delta x_{L} / r_{P}$ is established in the case wherein the adhesion point is located on the back of the particle $\left(\beta_{\mathrm{L}} \geq 90^{\circ}\right)$, and $\sin \beta_{L}=\Delta x_{L} / r_{P}$ is established in the case wherein the adhesion point is located on the front of the particle $\left(\beta_{\mathrm{L}} \leq 90^{\circ}\right)$. Therefore, $\beta_{\mathrm{L}}$ is expressed using Eq. (3) or (4)

$$
\begin{gathered}
\beta_{L}=180^{\circ}-\sin ^{-1}\left(\frac{\Delta x_{L}}{r_{P}}\right) \quad\left(\beta_{\mathrm{L}} \geq 90^{\circ}\right) \\
\beta_{L}=\sin ^{-1}\left(\frac{\Delta x_{L}}{r_{P}}\right) \quad\left(\beta_{\mathrm{L}} \leq 90^{\circ}\right) \ldots \ldots . . .
\end{gathered}
$$

It is same for the separation angle at the right side of the particle, $\beta_{\mathrm{R}}\left(^{\circ}\right)$. The average value of $\beta_{\mathrm{L}}$ and $\beta_{\mathrm{R}}$ is $\beta_{\text {ave }}$, and relation between $\beta_{\text {ave }}$ and $\mathrm{v}_{\mathrm{P} 0}$ or between $\beta_{\text {ave }}$ and $\theta$ were analyzed.

In addition, the height of the residual bubble on the particle was defined as the distance from the middle point between $\mathrm{X}_{\mathrm{L}}$ and $\mathrm{X}_{\mathrm{R}}\left(\mathrm{X}_{\mathrm{L}}\right.$ and $\mathrm{X}_{\mathrm{R}}$ are adhesion points of the air column remained on the particle) to the tip of the residual air column just after the rupture of the air column, as shown in Fig. 14(b). Increasing the height of the residual bubble implies that the air column ruptures at a position away from the back side of the particle. Relation between the height of the residual bubble and $\beta_{\text {ave }}$ were also analyzed.

The effect of $\mathrm{V}_{\mathrm{P} 0}$ on $\beta_{\mathrm{ave}}$ is shown in Fig. 15. The tendency that $\beta_{\text {ave }}$ decreased with an increasing $\mathrm{v}_{\mathrm{P} 0}$ or $\theta$ was considered. In addition, the tendency that decreasing the $\beta_{\text {ave }}$ increased the height of the residual bubble was considered, as shown in Fig. 16, and increased $d_{B}$, as shown Fig. 17. The cause behind the increasing $\mathrm{d}_{\mathrm{B}}$ is supposed that increasing the $\mathrm{V}_{\mathrm{P} 0}$ or $\theta$ increases the width of the air column by preventing the liquid film from spreading on the particle

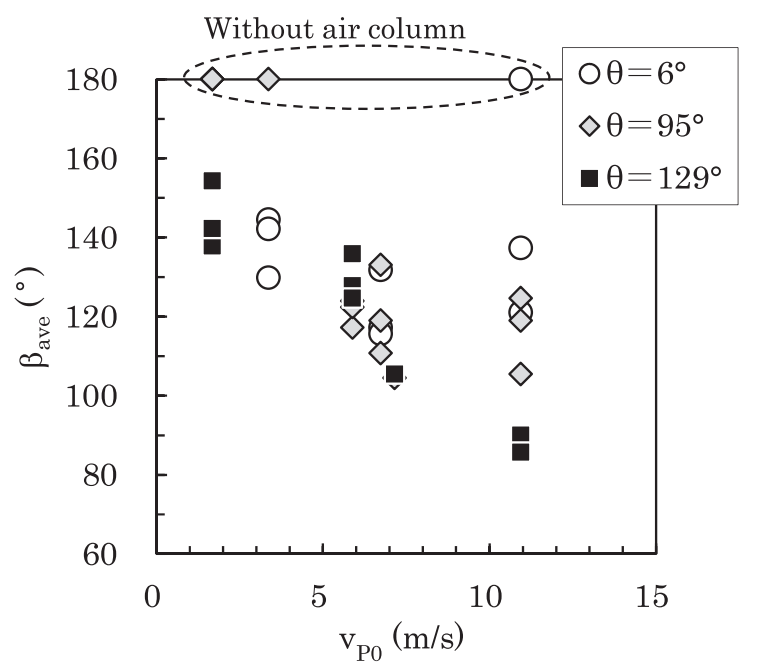

Fig. 15. Effect of particle velocity before penetration on separation angle of an air column. and the air column tends to rupture at a position away from the back side of the particle. Thus, it was clarified that $d_{B}$ is controlled by $\beta_{\text {ave }}$ although $\mathrm{V}_{\mathrm{P} 0}$ or $\theta$ is different.

Sakai and Iguchi reported that $\beta$ decreased upon increasing the modified Froude number, $\operatorname{Fr}^{*},\left(=\mathrm{V}_{\mathrm{P} 0}\left\{\rho_{\mathrm{P}} /\left(\rho_{\mathrm{L}} \cdot \mathrm{g} \cdot \mathrm{d}_{\mathrm{P}}\right)\right\}^{1 / 2}\right.$, $\mathrm{d}_{\mathrm{P}}$ : the diameter of the particle), which is the ratio of the inertial force and the buoyancy force. Therefore, increasing the $\mathrm{V}_{\mathrm{P} 0}$ increases and decreases the $\mathrm{Fr}^{*}$ and $\beta$, respectively, and the same results are obtained herein. However, effect of $\theta$ on $\beta$ cannot be explained by Fr $^{*}$. More investigation is necessary about effect of the contact angle on the wetting phenomena or behavior of the gas-liquid interface under a dynamic condition wherein the particle moves at high velocity.

\subsection{Effect of Contact Angle on Maximum Penetration Depth}

$\mathrm{L}_{\max }$ comprises the penetration depth from the water surface to the rupture point of the air column, and the penetration depth from the rupture point of the air column to the maximum depth. Effect of $\theta$ on them was analyzed. At first, the penetration depth from water surface to the rupture point

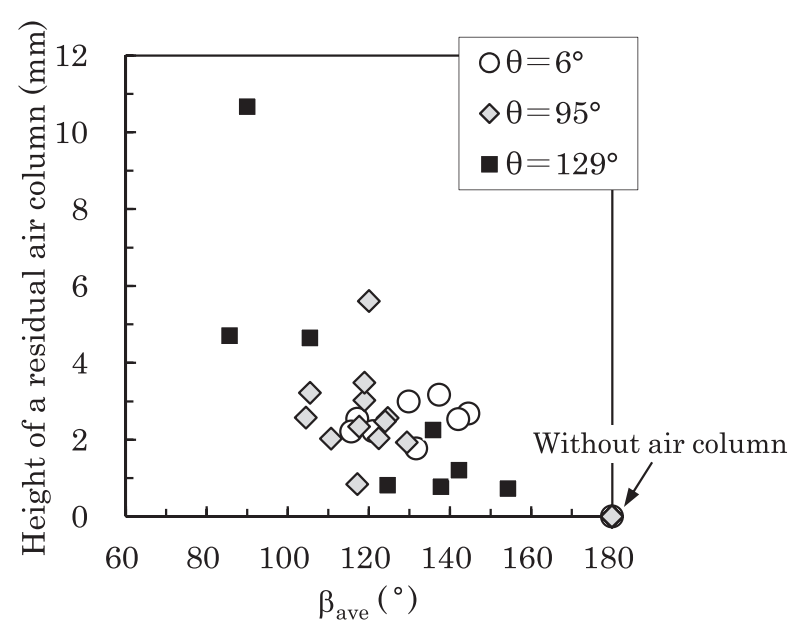

Fig. 16. Effect of separation angle of an air column on height of a residual air column on the particle.

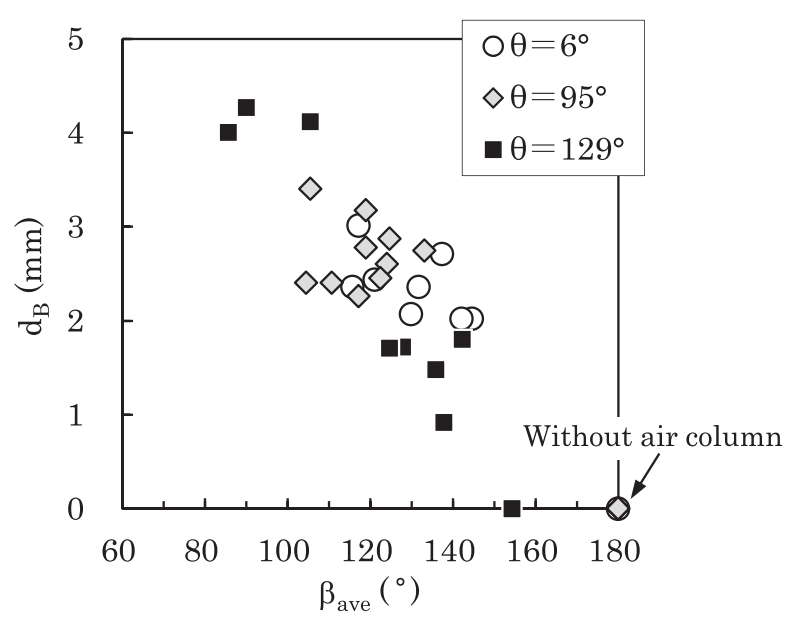

Fig. 17. Effect of separation angle of an air column on diameter of a residual bubble. 
of the air column (the air column rupture depth) is equal to the length wherein $1.6 \mathrm{~mm}$ is added to $\mathrm{H}_{\max }$. Therefore, the relation between $\mathrm{V}_{\mathrm{P} 0}$ and the air column rupture depth is almost the same as Fig. 7, and it suggests that the air column rupture depth at $\theta=129^{\circ}$ is slightly shorter than that at $\theta=$ $6^{\circ}$ or $95^{\circ}$. The particle experiences the buoyancy forces, the drag force, and the force caused by the interfacial tension; however, the effect of the buoyancy force does not change because difference of the density between the particle and the liquid is constant herein. Moreover, increasing the $\theta$ decreases the drag force and consumption of the kinetic energy because the adhesion work decreases and the interface between the particle and the liquid becomes slippery. ${ }^{29)}$ Therefore, the effect of wettability on the air column rupture depth cannot be explained by the drag force. With regard to effect of the interfacial tension, the force caused by surface tension, F, is expressed by Eq. (5) because it is product of the contact length between the air column and the particle, $\mathrm{L}$, and the vertical component of the surface tension, $\sigma_{\mathrm{y}}$, as shown in Fig. 18. F become maximum at $\beta=90^{\circ}$, where, $\sigma_{\mathrm{GL}}$ is $0.073 \mathrm{~N} / \mathrm{m}^{28)}$
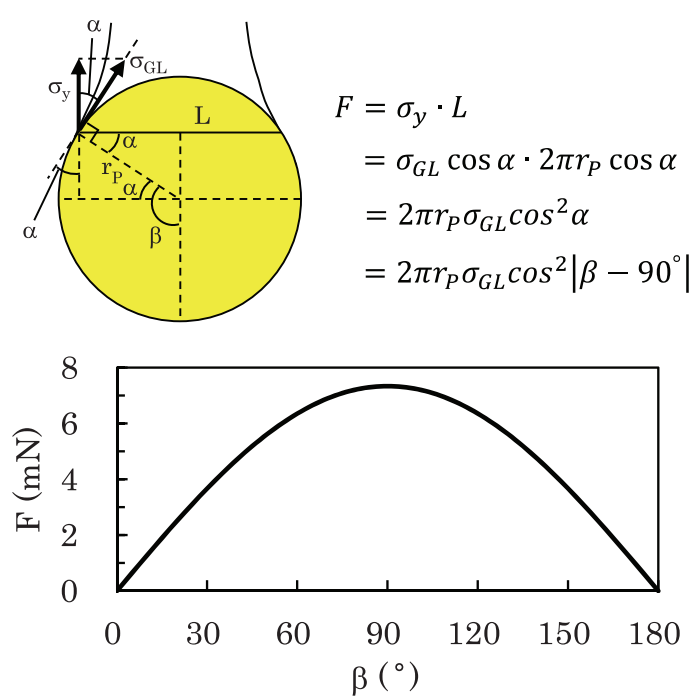

Fig. 18. Effect of separation angle of an air column on the force caused by surface tension of water. (Online version in color.)

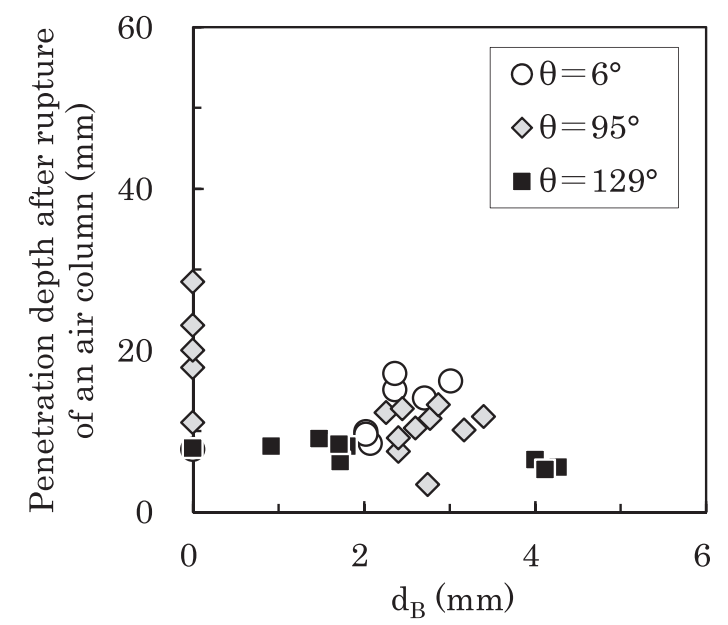

Fig. 19. Relation between diameter of a residual bubble and penetration depth after rupture of an air column.

$$
F=2 \pi r_{P} \sigma_{G L} \cos ^{2}\left|\beta-90^{\circ}\right|
$$

In Fig. $15, \beta_{\mathrm{ave}}$ decreases with an increasing $\mathrm{V}_{\mathrm{P} 0}$ at $\theta=129^{\circ}$ and $\mathrm{F}$ becomes almost maximum at $\mathrm{V}_{\mathrm{P} 0}=7.2-10.9 \mathrm{~m} / \mathrm{s}$ because $\beta_{\text {ave }}$ is $86-106^{\circ}$. Therefore, it is supposed that the force caused by the surface tension affects the air column rupture depth, and the adhesion point of the air column on the particle is an important factor related to the air column rupture depth as well as the residual bubble.

Next, the effect of $\theta$ on the penetration depth from the rupture point of the air column to the maximum depth is analyzed. The particle experiences the buoyancy forces and the drag force in water. Relation between $d_{B}$ and the penetration depth after rupture of the column is shown in Fig. 19. The correlation is not considered between them. Therefore, the penetration depth after rupture of the air column is not considerably different although $\mathrm{d}_{\mathrm{B}}$ increases and the buoyancy force increases. In addition, the tendency that the penetration depth after rupture of the air column decreased with increasing $\theta$ at same $\mathrm{d}_{\mathrm{B}}$ was considered. Therefore, effect of the drag force is minor, and it is supposed that effect of $\theta$ on the penetration depth after rupture of the air column is also minor.

From these discussions in this section, it is estimated that the effect of $\theta$ on $\mathrm{L}_{\max }$ is due to increasing the force caused by the surface tension during generation and rupture of the air column. Moreover, the separation angle just before rupture of the air column is used herein; however, the change of the adhesion point of the air column during particle penetration should be considered strictly. The air column ruptured at $0.012-0.028 \mathrm{~s}$ after particle penetration. More investigation is necessary about the change of the adhesion point of the air column in such a short period of time.

\section{Conclusions}

To elucidate the effect of wettability of the particle on penetration and flotation behaviors, the water model experiment blasting a single particle onto the water surface was performed. The particle penetration depth and detention time in the water was investigated, and the controlling factor of the residual bubble concerning in the detention time on the particle or generation of the air column causing the residual bubble was analyzed. Also, the mechanism that the diameter of the residual bubble and the penetration depth differed by wettability was discussed. Results obtained from these investigations are as follows:

(1) The poorly wetted particle floated on the water surface in a short period of time because the maximum penetration depth was short and the residual bubble was large. Conversely, the wetted particle exhibited a long detention time because the maximum penetration depth was long and the residual bubble detached from the particle.

(2) The threshold particle velocity of generating the air column herein was lower than the value measured in previous research that implemented at free fall condition. This was attributed to the water surface being deformed by career gas and the air column being generated easier than that in free fall condition.

(3) The diameter of the residual bubble increased upon increasing the particle velocity before penetration or the 
contact angle. It is because that the adhesion point of the air column on the particle changes toward to the penetrating direction of the particle and that the width and height of the residual bubble after rupture of the air column increase.

(4) The air column rupture depth was short in the case of the poorly wetted particle. It is because the force caused by the surface tension increases owing to the change of the adhesion point of the air column toward to the penetrating direction of the particle, and the maximum penetration depth also decreases. Conversely, the effect of the contact angle on the penetration depth after the rupture of the air column was not considered.

\section{REFERENCES}

1) S. Kitamura, Y. Mizukami, T. Kaneko, T. Yamamoto, R. Sakomura, E. Aida and S. Onoyama: Tetsu-to-Hagané, 76 (1990), 1801 (in Japanese). https://doi.org/10.2355/tetsutohagane1955.76.11 1801

2) A. Sakai, T. Tokoro and T. Hirata: Tetsu-to-Hagané, 81 (19̄95), T21 (in Japanese)

3) T. Nozaki, K. Nakanishi, H. Morishita, S. Yamada and F. Sudo: Tetsu-to-Hagané, 68 (1982), 1737 (in Japanese). https://doi. org/10.2355/tetsutohagane1955.68.13 1737

4) Y. Hara, H. Kitaoka, T. Sakuraya, T. Nozaki and H. Nishikawa: Tetsuto-Hagané, 74 (1988), 823 (in Japanese). https://doi.org/10.2355/ tetsutohagane1955.74.5_823

5) K. Endoh, H. Takamoto, J. Nakagawa, Y. Obana, H. Takahama, T. Kaneko, A. Inaba and T. Yamamoto: Seitetsu Kenkyu, 335 (1989), 20 (in Japanese).

6) H. Okano, Y. Tajiri, M. Sato, S. Fukagawa and K. Shinme: Sumitomo Met., 50 (1998), 65 (in Japanese)

7) T. Kirihara, K. Aizawa and Y. Kato: Tetsu-to-Hagané, 89 (2003), 827 (in Japanese). https://doi.org/10.2355/tetsutohagane1955.89.8_827

8) T. Kirihara, H. Uehara, H. Nakato and Y. Kato: Tetsu-toHagané, 89 (2003), 1018 (in Japanese). https://doi.org/10.2355/ tetsutohagane 1955.89.10 1018

9) T. A. Engh, K. Larsen and K. Venas: Ironmaking Steelmaking, 6 (1979), 268.

10) E. Kimura: Trans. Iron Steel Inst. Jpn., 23 (1983), 522. https://doi.org/ 10.2355/isijinternational1966.23.522

11) Y. Ozawa, K. Suzuki and K. Mori: Tetsu-to-Hagané, 69 (1983), 753 (in Japanese). https://doi.org/10.2355/tetsutohagane1955.69.7_753

12) J. G. Lee and M. Tokuda: Trans. Iron Steel Inst. Jpn., 28 (198̄), 278. https://doi.org/10.2355/isijinternational1966.28.278

13) T. Okuno, M. A. Uddin, Y. Kato, S. B. Lee and Y. H. Kim: ISIJ Int., 57 (2017), 1902. https://doi.org/10.2355/isijinternational. ISIJINT-2017-336

14) K. Narita, T. Makino, H. Matsumoto and K. Ogawa: Tetsu-toHagané, 69 (1983), 392 (in Japanese). https://doi.org/10.2355/ tetsutohagane1955.69.3 392

15) T. Oda, T. Inoue and I. Hoshikawa: Kobe Steel Eng. Rep., 56 (2006), 32 (in Japanese).

16) K. Ogawa, T. Onoye, H. Matsumoto and K. Narita: Tetsu-to-Hagané, 71 (1985), A29 (in Japanese).

17) K. Ogawa, T. Makino, H. Matsumoto, T. Onoye and K. Narita: Trans. Iron Steel Int. Jpn., 25 (1985), 1220. https://doi.org/10.2355/ isijinternational1966.25.1220

18) N. Shimamoto, M. Iguchi, T. Uemura and N. Yonehara: Mater. Trans., 45 (2004), 910. https://doi.org/10.2320/matertrans.45.910

19) M. Tanaka, M. Hashimoto, R. Tsujino and M. Iguchi: J. Jpn. Soc. Exp. Mech., 8 (2008), 201 (in Japanese). https://doi.org/10.11395/ jjsem.8.201

20) M. Tanaka, R. Tsujino, A. Hiratsuka and M. Iguchi: J. Jpn. Soc. Exp. Mech., 9 (2009), 265 (in Japanese).

21) Y. Sakai and M. Iguchi: Tetsu-to-Hagané, 98 (2012), 1 (in Japanese). https://doi.org/10.2355/tetsutohagane.98.1

22) C. Duez, C. Ybert, C. Clanet and L. Bocquet: Nat. Phys., 3 (2007), 180. https://doi.org/10.1038/nphys545

23) K. Katoh, R. Minami, T. Wakimoto, Y. Ueda and M. Iguchi: Jpn. J. Multiph. Flow, 28 (2015), 547 (in Japanese). https://doi.org/10.3811/ jjmf.28.547

24) M. Nakano and K. Ito: ISIJ Int., 56 (2016), 1537. https://doi.org/ 10.2355/isijinternational.ISIJINT-2016-183

25) M. Nakata and T. Inamuro: Proc. 30th Symp. on Computational Fluid Dynamics, The Japan Society of Fluid Mechanics, Tokyo, (2016), B05-4 (in Japanese)

26) A. Matsuzawa, K. Sasai, H. Harada and M. Numata: ISIJ Int., 58 (2018), 2288. https://doi.org/10.2355/isijinternational.ISIJINT-2018-400

27) Kagaku-Binran Kisohen (Handbook of Chemistry: Pure Chemistry), 3rd ed., Vol. II, ed. by The Chemical Society of Japan, Maruzen, Tokyo, (1991), 90 (in Japanese).

28) Kagaku-Binran Kisohen (Handbook of Chemistry: Pure Chemistry), 3rd ed., Vol. II, ed. by The Chemical Society of Japan, Maruzen, Tokyo, (1991), 81 (in Japanese).

29) H. Sakao and K. Mukai: Tetsu-to-Hagané, 63 (1977), 513 (in Japanese). https://doi.org/10.2355/tetsutohagane1955.63.3_513 